\title{
POSSIBILIDADES DE DESAFETAÇÃO E RECATEGORIZAÇÃO EM UNIDADES DE CONSERVAÇÃO DE PROTEÇÃO INTEGRAL: AS UCS DA PORÇAO CENTRAL DO MOSAICO DO ESPINHAÇO (MINAS GERAIS/BRASIL)
}

\author{
DOWNGRADING AND DOWNSIZING POSSIBILITES IN PROTECTEC \\ AREAS OF INDIRECT USES: THE PAS OF CENTRAL REGION IN THE \\ ESPINHAÇO MOSAIC (MINAS GERAIS/BRASIL)
}

POSSIBILITÉS DE DÉSAFFECTATION ET RECATÉGORISATION DANS LES UNITÉS DE PRÉSERVATION DE PROTECTION INTÉGRALE: LES UPS DE LA PARTIE CENTRALE DU MOSAÏQUE DU ESPINHAÇO

\section{Raquel Faria Scalco}

Mestre em Geografia pela Universidade Federal de Minas Gerais (UFMG) e Doutoranda do Programa de Pós-Graduação em Geografia da Universidade Federal de Minas Gerais (UFMG). Professora Assistente do curso de Turismo da Faculdade Interdisciplinar em UFVJM. Av. João Antunes de Oliveira $n^{\circ} 795$. Cazuza.Diamantina/MG. CEP 39100-000.E-mail: raquel.scalco@yahoo.com.br

\section{Bernardo Machado Gontijo}

Mestre em Estudos Latino Americanos, pela Vanderbilt University (1992); Doutor em Desenvolvimento Sustentável, pela Universidade de Brasília (2003). Professor Associado do Instituto de Geociências da Universidade Federal de Minas Gerais. Departamento de Geografia - Instituto de Geociências / UFMG. Campus Pampulha Av. Antônio Carlos 6627 - Belo Horizonte / MG.CEP 31270-901. E.mail:gontijobm@yahoo.com.br

\section{RESUMO}

A criação de Unidades de Conservação (UCs) é uma importante estratégia para assegurar a conservação dos recursos naturais e a proteção da biodiversidade, porém, muitas vezes a forma como são criadas gera conflitos entre comunidades e órgãos gestores. Este é o caso de muitas UCs de proteção integral da porção central do Mosaico do Espinhaço, onde vivem inúmeras comunidades rurais (tradicionais ou não) que historicamente utilizam recursos de áreas onde foram criadas UCs. Esta pesquisa pretende explicitar que, quando se tratam de povos e comunidades tradicionais que vivem ou utilizam recursos de UCs de proteção integral, a melhor alternativa é a flexibilização por meio de acordos, pactos ou termos de compromissos, para evitar perdas maiores advindas da desafetação, redução de limites ou recategorização da área. Para tanto, foram utilizados como procedimentos metodológicos a pesquisa bibliográfica, pesquisa documental, trabalhos de campo e participação em reuniões técnicas e de conselhos gestores.

Palavras-chave: Unidades de Conservação; Comunidades Tradicionais; Mosaico do Espinhaço. 


\begin{abstract}
The creation of Protected Areas (PAs) is an important strategy to ensure the conservation of natural resources and for biodiversity protection. The way that they are created, however, leads to conflicts between communities and management institutions. This is the case of many protected areas in the central region of the Espinhaço Mosaic (MG/ Brazil), where many rural communities (whether traditional or not) historically use resources from areas defined as protected. This research intends to make explicit that, when dealing with traditional peoples and communities that live or use resources of PAs, the best alternative is to flexibilize through agreements, pacts or terms of commitments, in order to avoid major losses resulting from Protected area downgrading, downsizing, and degazettement. It was adopted different methodological proceedings: bibliographic research, analysis of documents, field works, and participation in technical meetings and management councils.
\end{abstract}

Keywords: Protected Areas; Traditional Communities; Espinhaço Mosaic

\title{
RÉSUMÉ
}

L'aménagement des Unités de Préservation (UPs) est une stratégie importante pour assurer la préservation des recours naturels et la protection de la biodiversité. Néanmoins, la façon de les mettre en place provoque souvent des conflits entre les communautés et les institutions responsables de la gestion. C'est le cas de plusieurs UPs de protection intégrale de la partie centrale de la Mosaïque du Espinhaço, où vivent de nombreuses communautés rurales (traditionnelles ou pas) qui utilisent les recours des espaces où des UPs ont été créées il y a longtemps. Cette recherche vise à préciser que, lorsqu'il s'agit de collectivités traditionnelles vivant ou utilisant des recours de UPs de protection intégrale, mieux vaut avoir recours à l'aménagement flexible par l'intermédiaire de conventions, des accords ou bien des engagements formels afin d'éviter des pertes issues de la désaffectation, reduction de limites ou recatégorisation de l'espace. A cet effet, comme procédure méthodologique, nous avons utilisé la recherche bibliographique, la recherche documentaire, le travail sur le terrain et la participation aux réunions techniques et des conseils gestionnaires.

Mots-clés: Unité de Préservation; Communautés Traditionnelles; Mosaïque du Ư $\underset{\substack{x \\ 0}}{x}$ Espinhaço. 


\section{INTRODUÇÃO}

A Cadeia do Espinhaço é considerada uma das regiões de maior biodiversidade de Minas Gerais, elevado grau de endemismos e área de nascentes de importantes rios brasileiros. Esta área foi reconhecida pela UNESCO como Reserva da Biosfera e foi considerada como área prioritária para conservação e onde devem ser criadas e ampliadas Unidades de Conservação (UCs) (COSTA et al. 1998; DRUMMOND et al. 2005 apud GONTIJO, 2008). Visando garantir a proteção deste frágil e relevante ambiente, foram criadas inúmeras unidades de conservação, além do Mosaico de Áreas Protegidas do Espinhaço: Alto Jequitinhonha - Serra do Cabral, que tem o objetivo de aumentar a capacidade de efetivação das metas propostas para a conservação da região.

A área central do Mosaico do Espinhaço passou por um processo intenso de exploração de Diamantes nos séculos XVIII e XIX, que marca ainda hoje a forte tradição cultural desta população. A renda da maioria das famílias se dá pelo complemento de mais de uma atividade, dentre elas a agricultura de subsistência, a coleta e venda de sempre-vivas, a criação de gado e o garimpo artesanal. Esta diversidade de atividades elucida os diferentes tipos de relações que os moradores estabelecem com o território e a grande dependência em relação aos recursos naturais (SOUZA et al, 2013; MENDONÇA, 2013).

Nesta região, estão localizadas muitas comunidades rurais, algumas delas reconhecidas como povos tradicionais (quilombolas e apanhadores de flores sempre-vivas) e que tiveram diversas atividades cerceadas em função da presença de UCs de proteção integral e do aumento da fiscalização ambiental na área. Isso tem gerado inúmeros conflitos que podem findar em processos de recategorização e redefinição de limites de algumas UCs da área central do Mosaico do Espinhaço. Em função dessa possibilidade, suscita-se a necessidade de se discutir a necessária flexibilização da proteção integral quando se tratam de comunidades tradicionais vivendo ou utilizando permanente ou temporariamente áreas de UCs. Tal colocação se justifica tendo em vista aquilo que estamos considerando como uma "epidemia" de processos que tramitam no Congresso visando diminuir o status de proteção por meio de recategorização, desafetação ou redução de limites de UCs em todo o território brasileiro.

A presente pesquisa teve como foco a área central do Mosaico do Espinhaço, abrangendo as seguintes unidades de conservação: Parque Nacional das Sempre Vivas, Parque Estadual do Biribiri, Parque Estadual do Pico do Itambé; Parque Estadual do Rio Preto; APA Estadual das Águas Vertentes e o Monumento Natural Estadual Várzea do Lajeado e Serra do Raio, bem como as áreas de entorno dessas UCs onde estão localizados os territórios das comunidades quilombolas Mata dos Crioulos (interior da APA das Águas Vertentes e 
entorno dos Parques Estaduais do Rio Preto e do Pico do Itambé); Vargem do Inhaí (zona de amortecimento do Parque Nacional das Sempre-Vivas); Quartel do Indaiá (entorno do Parque Nacional das Sempre-Vivas); Baú, Ausente, Vila Nova e Santa Cruz (interior da APA das Águas Vertentes e próximas ao Monumento Natural Estadual Várzea do Lajeado e Serra do Raio). Além da presença dos quilombolas, a área onde hoje estão localizadas todas as UCs acima citadas era tradicionalmente utilizada por apanhadores de flores semprevivas, categoria esta recentemente reconhecida como povos e comunidades tradicionais.

As atividades econômicas tradicionalmente desenvolvidas por essas comunidades foram proibidas com a criação das UCs, principalmente no que se refere ao garimpo e à coleta de sempre-vivas (e de outras espécies vegetais), o que gerou um grande conflito com os órgãos gestores das UCs. A partir desse conflito, vieram à tona processos judiciais, audiências públicas, grupos de trabalho e mesas de diálogo na tentativa de solucionar os problemas, que ainda persistem e que podem terminar com processos de redução de limites e recategorização de algumas das UCs aqui analisadas, podendo trazer diversos danos ambientais para a região.

Assim, esta pesquisa tem como objetivo refletir sobre a necessidade de flexibilização da proteção integral quando se tratam de usos feitos por comunidades tradicionais, utilizando as UCs da porção central do Mosaico do Espinhaço como estudos de caso que apontam para a necessidade de discussões mais ampla sobre desafetação e recategorização em unidades de conservação de proteção integral.

Para tanto, utilizou-se como metodologia a revisão bibliográfica, pesquisa documental, trabalhos de campo e acompanhamento de reuniões técnicas e de conselhos de UCs e do Mosaico do Espinhaço.

Desta forma, espera-se contribuir para a construção de um arcabouço teórico capaz de embasar tanto gestores como comunidade no que se refere à possibilidade de conciliação e flexibilização da proteção integral para garantir a continuidade da reprodução social das comunidades tradicionais que vivem no entorno das UCs do Mosaico do Espinhaço, bem como garantir a continuidade da proteção da biodiversidade por meio das UCs já criadas sem diminuição do status de proteção ou da área abrangida por elas.

\section{METODOLOGIA}

Este artigo é fruto de vários anos de trabalho junto às UCs da porção central do Mosaico de Áreas Protegidas do Espinhaço. Estes trabalhos foram realizados em função da atuação dos autores como professores do curso de Turismo da UFVJM e dos cursos de geografia 
e turismo da UFMG, atuando nesta região por meio de projetos de pesquisa, extensão, trabalhos de campo, orientações de trabalhos de conclusão de curso e representação junto aos conselhos consultivos de UCs e do Mosaico do Espinhaço. Mais recentemente, um dos autores tem desenvolvido pesquisas na área em função, também, de seu doutoramento junto ao programa de pós-graduação em Geografia da UFMG.

O presente artigo é fruto também de extensa revisão bibliográfica em teses e dissertações sobre as UCs presentes nesta área do Mosaico do Espinhaço, e da leitura e análise de documentos técnicos como planos de manejo e relatórios de atividades das UCs aqui analisadas. Vale citar alguns materiais que foram fundamentais para subsidiar as análises aqui realizadas, a saber:

- Sobre o Parque Estadual do Biribiri: SOUZA, SCALCO e XAVIER (2012); SOUZA (2011); e STPC Engenharia de Projetos LTDA (2004).

- Sobre o Parque Estadual do Pico do Itambé: ABREU (2015); e STPC Engenharia de Projetos LTDA (2004a).

- Sobre o Parque Estadual do Rio Preto: MORAIS (2014); RIBEIRO (2013); e STPC Engenharia de Projetos LTDA (2004b).

- Sobre a APA Estadual das Águas Vertentes: SOUZA (2014); LIMA et al (2015); MOTTA et al (2014); SCALCO e SOUZA (2016).

- Sobre o Parque Nacional das Sempre-Vivas: MONTEIRO (2011); ICMBIO (2016).

- Sobre o Monumento Natural Estadual Várzea do Lajeado e Serra do Raio: IEF (2010) e IEF (2015).

Outro procedimento metodológico adotado foi a revisão bibliográfica sobre Unidades de Conservação; seus instrumentos de gestão; desafetação, recategorização, redução de limites e dupla afetação; direito de povos e comunidades tradicionais; e aspectos legais relacionados a estes temas.

Foram feitos ainda diversos trabalhos de campo para conhecimento da realidade local, com conversas com a comunidade, uso de GPS e câmera fotográfica para registro das informações coletadas.

Além disso, houve o acompanhamento de algumas reuniões de Conselhos Gestores de UCs, do Conselho do Mosaico do Espinhaço e das Mesas de Diálogo instituídas para tratar dos conflitos entre UCs da região e as comunidades tradicionais extrativistas. 
Seguindo as etapas metodológicas acima explicitadas foi possível compreender os aspectos legais relacionados à UCs e povos e comunidades tradicionais, com base em extensa revisão bibliográfica e pesquisa sobre leis que tratam desses temas. Além disso, foi possível refletir sobre os desdobramentos em casos de sobreposições entre territórios tradicionais e UCs de proteção integral, cruzando dados coletados por meio da pesquisa bibliográfica e em documentos legais, com as discussões realizadas em reuniões técnicas e de conselhos.

\section{AS UCS DA PORÇÃO CENTRAL DO MOSAICO DE ÁREAS PROTEGIDAS DO ESPINHAÇO E AS COMUNIDADES RURAIS DO ENTORNO: ASPECTOS AMBIENTAIS, INSTRUMENTOS DE GESTÃO DAS UCS E CARACTERÍSTICAS SOCIOECONÔMICAS DAS COMUNIDADES.}

A Serra do Espinhaço é um conjunto de terras altas, na forma de bumerangue, com orientação norte-sul e convexidade para oeste, que se estende por cerca de $1200 \mathrm{~km}$ da região central de Minas Gerais até o norte da Bahia. É um grande divisor de águas entre as bacias hidrográficas do centro-leste brasileiro e a do rio São Francisco (SAADI, 1995, p.41). Além disso, configura-se também como um divisor de biomas localizado entre a Mata Atlântica (à Leste), o Cerrado (à Oeste) e a Caatinga (ao Norte), sendo entendido por Gontijo (2008), como o lócus de um quarto bioma mineiro - os campos rupestres de altitude.

Esta é uma área de grande importância ecológica, sendo considerada uma das regiões de maior biodiversidade de Minas Gerais (contendo mais de seis mil espécies da flora e fauna), elevado grau de endemismos e área de nascentes de rios que abastecem importantes bacias hidrográficas brasileiras. Em função dessas características, a região da Serra do Espinhaço foi considerada nas duas edições dos atlas para a conservação da biodiversidade em Minas Gerais como uma das áreas prioritárias de conservação e onde devem ser criadas e ampliadas Unidades de Conservação (COSTA et al. 1998; DRUMMOND et al. 2005 apud GONTIJO, 2008). Além disso, foi considerada pelo WWF (World Wide Fund for Nature) e pela IUCN (International Union for Conservation of Nature) como um dos centros de diversidade biológica do Brasil, devido ao seu alto grau de endemismos e como um centro de diversidade genética das eriocauláceas, principal família botânica do grupo das semprevivas (ICMBIO, 2016).

Em função dessas características, a Serra do Espinhaço foi reconhecida pela UNESCO como Reserva da Biosfera (RBSE), em 2005. A principal justificativa para a criação da RBSE é a gestão integrada do território, com o objetivo de avançar nos programas de conservação da natureza, aliados ao desenvolvimento sustentável das comunidades locais, em uma área tão especial, do ponto de vista ecológico e sociocultural.

a 
Visando aumentar os níveis de conservação desta área, foi criado na região do Espinhaço Meridional o Mosaico de Áreas Protegidas do Espinhaço: Alto Jequitinhonha - Serra do Cabral (doravante chamado de Mosaico do Espinhaço), com o objetivo de aumentar a capacidade de efetivação das metas propostas para a conservação da região, por meio da gestão integrada e participativa de Unidades de Conservação próximas, justapostas ou sobrepostas. O Mosaico de UCs é uma ferramenta de gestão integrada, instituída pelo Sistema Nacional de Unidades de Conservação (SNUC), visando compatibilizar a presença da biodiversidade, a valorização da sociodiversidade e o desenvolvimento sustentável no contexto regional.

A área de influência do Mosaico do Espinhaço possui aproximadamente 1.900.000 hectares, abrangendo total ou parcialmente 24 municípios e 19 Unidades de Conservação, como pode ser visto no mapa da figura abaixo.

Figura 1: O Mosaico do Espinhaço com as Unidades de Conservação e municípios por ele abrangidos.

Figura 1 - Unidades de conservação e municípios que integram o Mosaico do Espinhaço

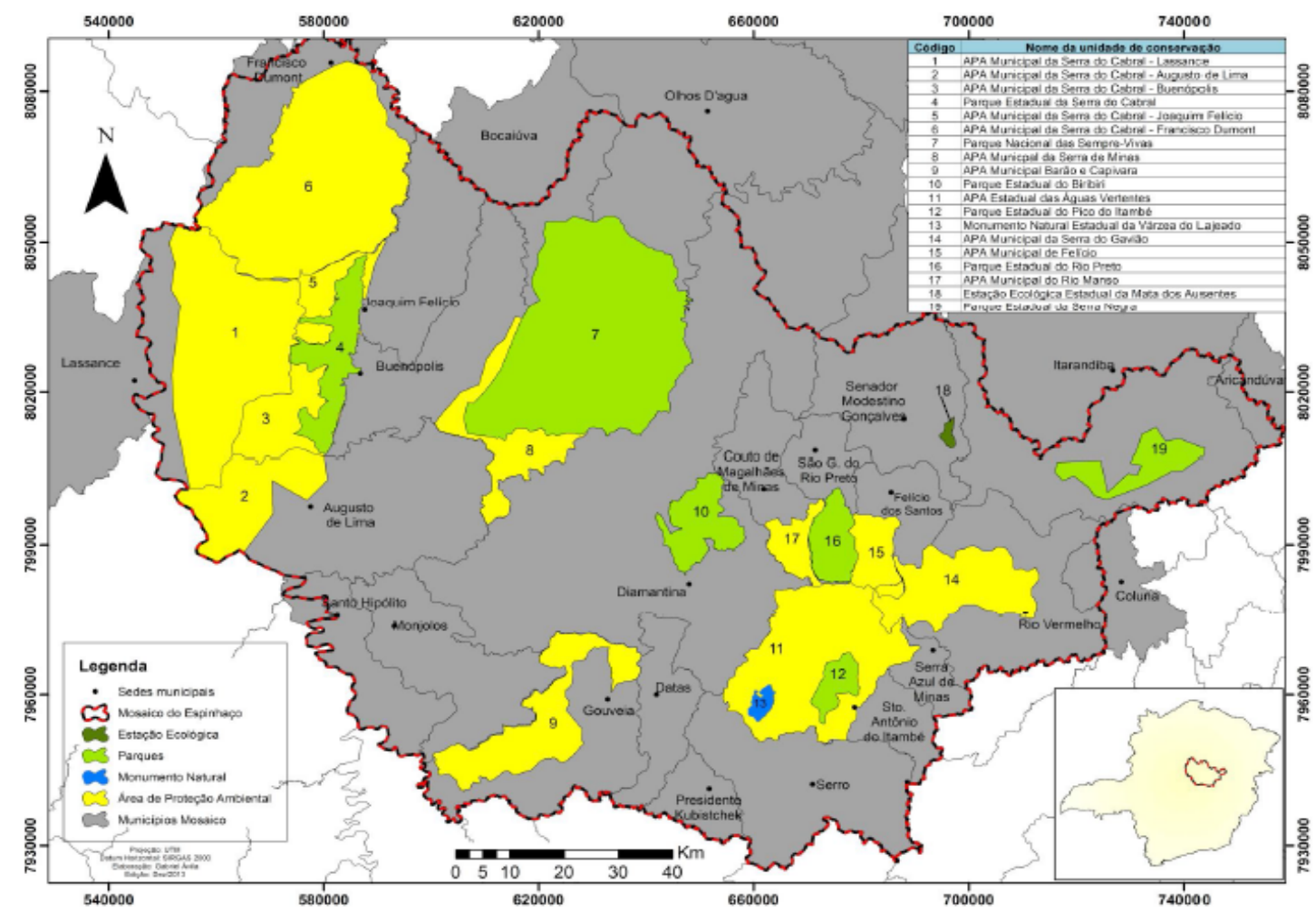

Fonte: Ribas e Gontijo (2015).

A área central do Mosaico do Espinhaço, objeto de estudo da presente pesquisa, abrange as seguintes Unidades de Conservação: Parque Nacional das Sempre-Vivas (PNSV), Parque Estadual do Pico do Itambé (PEPI), Parque Estadual do Biribiri (PEBI), Parque Estadual do Rio Preto (PERP), APA Estadual das Águas Vertentes (APAEAV), Monumento Natural 
Estadual Várzea do Lajeado e Serra do Raio, APA Municipal Serra do Gavião, APA Municipal Rio Manso e APA Municipal Felício. Em função da ausência de dados e do baixo grau de efetividade das APAs Municipais, elas não foram consideradas nesse estudo.

As UCs aqui analisadas possuem algumas características semelhantes, tanto no que se refere aos aspectos ambientais, como aos processos de criação e gestão, e ainda os relativos às características socioeconômicas das comunidades rurais que vivem dentro ou no entorno das mesmas. As análises aqui realizadas sobre os aspectos supracitados foram realizadas com base nos planos de manejo e teses e dissertações sobre as UCs, conforme apontado na metodologia. Além disso, a participação dos autores em reuniões de conselhos, desenvolvimento de pesquisas com realização de trabalhos de campo nas UCs ${ }^{1}$ permitiram enriquecer as analises e discussões aqui realizadas.

Destaca-se que a porção central do Mosaico do Espinhaço, e por conseqüência as UCs aqui analisadas, possuem áreas desde o domínio da Mata Atlântica até o do Cerrado, sendo a Serra do Espinhaço, com seus campos rupestres, o elemento geográfico desta transição (ÁVILA, 2014 e GONTIJO, 2008). As UCs desta região possuem diversas espécies da flora e fauna endêmicas, e outras tantas raras, ou ameaçadas de extinção. Além disso, a questão hídrica é preponderante em todas elas, sendo que nesta área do Mosaico estão localizadas importantes nascentes e córregos que abastecem as bacias hidrográficas dos rios São Francisco, Doce e Jequitinhonha. Sendo assim, o Mosaico do Espinhaço se configura também como um importante divisor de bacias hidrográficas.

Apesar de toda essa relevância ambiental e ecológica, as UCs dessa região vêm sofrendo com inúmeros problemas ambientais advindos do desmatamento, da extração vegetal e mineral, do uso inadequado do fogo e do pisoteio e compactação do solo pelo gado. Estes problemas são causados principalmente pela pressão que o capital exerce sobre os recursos naturais (com expansão de projetos mineradores e de monocultura de eucalipto, por exemplo) e pela criação de UCs sem consulta pública e em locais onde a comunidade tradicionalmente depende dos recursos naturais para subsistência. Em algumas delas está presente também a pressão da expansão urbana com loteamentos e empreendimentos turísticos na zona de amortecimento das mesmas (Parque Estadual do Biribiri e MONAT Várzea do Lajeado e Serra do Raio).

Como exemplo, podemos citar as seguintes pesquisas desenvolvidas pelos autores: SOUZA, SCALCO e XAVIER (2012); MOTTA et al (2014); LIMA et al (2015); SCALCO e SOUZA (2016); SCALCO e GONTIJO (2016); GONTIJO (2008); RIBAS e GONTIJO (2015); MORAIS et al (2013), GONTIJO (2016). 
A maior parte das UCs aqui analisadas foi criada antes da publicação da Lei nº.985/2000, que institui o SNUC, e, desta forma, não foram realizadas consultas públicas em seus processos de criação. De acordo com este instrumento legal, a criação de UCs deve ser precedida de estudos técnicos e de consulta pública à população local e a outras partes interessadas. As únicas UCs em que houve consulta pública antes de seu processo de criação foram o PARNA das Sempre-Vivas (com reunião em uma escola no distrito de Inhaí, sem representatividade perante a população total afetada, com o agravante de que a consulta pública foi realizada pela internet, em uma área onde este recurso tecnológico não estava e ainda não está disponível para a maior parte da população) e o MONAT Várzea do Lajeado e Serra do Raio.

Desta forma, as comunidades do entorno das UCs localizadas nesta área do Mosaico do Espinhaço sofreram um processo de cerceamento de suas atividades tradicionais pela criação das UCs, sem serem consultadas e/ou informadas anteriormente à criação das áreas protegidas. A maior parte das comunidades rurais no entorno dessas UCs ficou sabendo de sua existência quando chegaram as equipes dos órgãos ambientais e começaram a restringir o desenvolvimento de muitas atividades tradicionalmente desenvolvidas por eles e que constituíam-se em fonte complementar da renda de muitas famílias.

No que se refere ao Plano de Manejo e zoneamento da UC, a maior parte delas possui tais documentos, porém em muitos casos estão desatualizados, com erros ou com lacunas no que se refere ao conhecimento sobre a realidade local. O Plano de Manejo é o documento oficial de planejamento das UCs no Brasil. Este documento deve conter o diagnóstico da UC, assim como propostas de ações a serem implementadas pelo órgão gestor da mesma. O Zoneamento pode ser parte deste documento ou pode ser elaborado separadamente. Independentemente do formato, é importante ressaltar que no Zoneamento são estabelecidas áreas onde cada uso ou atividade pode ser desenvolvido, buscando-se estabelecer as diretrizes e orientações que visem assegurar tanto a conservação dos recursos naturais, como a melhoria da qualidade de vida da comunidade.

O PARNA das Sempre-Vivas (PNSV) é a UC que possui o melhor e mais atualizado plano de manejo entre as UCs dessa região, uma vez que o mesmo segue as orientações do Roteiro Metodológico para Planejamento deste tipo de UC (ICMBIO, 2011), tendo sido elaborado pela equipe gestora do Parque, com apoio de profissionais qualificados para a complementação de informações sobre alguns dos temas trabalhados no Plano de Manejo. 
Os Parques Estaduais do Biribiri (PEBI), Rio Preto (PERP) e Pico do Itambé (PEPI) tiveram seus planos de manejo elaborados no mesmo ano (2004), pela mesma empresa (STCP Engenharia de Projetos LTDA, de Curitiba/PR) e seguindo a mesma estrutura. Esses planos de manejo, de forma geral, contemplam os itens necessários a este documento, estando ausente apenas os encartes de Projetos Específicos e de Monitoria e Avaliação do Plano de Manejo, que estão previstos no Roteiro Metodológico para Planejamento deste tipo de UC (ICMBIO, 2011). Porém, esta orientação metodológica foi elaborada posteriormente ao plano de manejo, não podendo, portanto se adequar a ela.

Em relação aos planos de manejo dessas UCs estaduais, percebe-se que alguns temas foram tratados de forma muito superficial, sendo suscitada a possibilidade de que os trabalhos de campo foram insuficientes para o efetivo conhecimento necessário para a elaboração de um documento de tamanha importância, prevalecendo, em alguns casos, o uso de dados secundários. Ressalta-se a necessidade de revisão dos mesmos, em função de algumas lacunas que apresentam e também dado o tempo que se passou desde a sua elaboração, em 2004, sendo que foram realizados contemplando um horizonte de cinco anos. As demais UCs da região não possuem plano de manejo.

Outro importante instrumento de gestão instituído pelo SNUC é o Conselho Gestor de Unidade de Conservação. De acordo com a Lei n 9.985 , todas as categorias de UCs devem possuir conselhos gestores, sejam eles deliberativos ou consultivos. A função dos conselhos gestores de unidade de conservação é construir um espaço de discussão e negociação dos problemas e demandas socioambientais que envolvem as UCs, com a participação de todos os agentes implicados na sua gestão. Eles garantem a participação e o controle social na gestão e implementação de Unidades de Conservação.

Todas as UCs desta região possuem conselhos consultivos, sendo que os mesmos foram criados entre 2008 e 2011, e suas reuniões ordinárias ocorrem cerca de 3 a 4 vezes por ano. Apesar de existirem, os conselhos consultivos das UCs aqui analisadas cumprem parcialmente suas atribuições, em função da baixa participação das comunidades do entorno, dificuldades de deslocamento das mesmas, baixo nível de conhecimento técnico dos participantes, e de serem apenas parcialmente utilizados como lócus de reivindicação das demandas da comunidade. Estes conselhos, apesar de garantirem a participação social na gestão da UC, têm funcionado prioritariamente como lócus de disseminação de informações sobre a UC e/ou sobre ações da área ambiental na região. Assim, poderiam avançar ainda mais no que se refere ao alcance de muitos objetivos previstos para a UC, se houvesse um maior montante de recursos que viabilizassem o transporte dos comunitários e a capacitação dos conselheiros para que se tornem protagonistas nesse processo. Desta 
forma, seria possível diminuir as assimetrias de poder e de conhecimento, dotando os diferentes atores sociais de condições de equidade no exercício do diálogo e na busca de soluções consensuais para os problemas socioambientais identificados.

As UCs aqui analisadas, de forma geral possuem diversas carências relacionadas principalmente a recursos financeiros, materiais e humanos, o que se reflete diretamente no baixo nível de efetividade de gestão das mesmas, excetuando-se o PERP, avaliado com nível de efetividade de 87\% (ÁVILA, 2014).

O PERP destaca-se também como a UC com melhor infraestrutura, possuindo estrutura completa para recebimento e atendimento de turistas, pesquisadores, estudantes, e para garantir o desenvolvimento das atividades de conservação pela equipe gestora. As demais UCs da região possuem poucos equipamentos e escassa estrutura, que na maioria das vezes se resume à sede, portaria, veículos e equipamentos de uso pessoal.

Em função desta precariedade de recursos, as equipes gestoras têm atuado principalmente em ações que não demandam muito recurso e que são fundamentais para a conservação da área, como combate a incêndios florestais, educação ambiental, fiscalização e divulgação da UC.

No que se refere à regularização fundiária, nenhuma UC que não admite a presença humana em seu interior concluiu 100\% este processo, sendo que o PERP e o PEPI foram os que mais avançaram neste sentido. O PERP está com a situação regularizada, porém, recentemente a comunidade quilombola Mata dos Crioulos está requerendo cerca de 4.440 hectares como seu território de uso tradicional para a coleta de sempre-vivas. Em relação ao PEPI, falta a regularização da situação de um único morador que ainda se encontra no interior da UC, havendo também uma pequena parte da UC sendo reivindicada como território pela comunidade quilombola Mata dos Crioulos. O PNSV e o PEBI ainda não iniciaram seus processos de regularização fundiária e as demais UCs não precisam retirar a população de seu interior.

Apesar da maior parte das UCs aqui analisadas serem criadas tendo como um dos principais objetivos o desenvolvimento do turismo, apenas o Parque Estadual do Rio Preto está totalmente equipado e organizado para o desenvolvimento desta atividade. Deve-se destacar que o potencial turístico regional é imenso, principalmente no que se refere ao turismo em contato com a natureza, sendo que em todas as UCs existem diversos atrativos turísticos interessantes, como cachoeiras, picos, serras, grutas, lapas, pinturas rupestres, trilhas, dentre outros. Porém, a escassez de equipamentos adequados e de recursos humanos para o acompanhamento dos turistas, bem como a falta de regularização fundiária e as dificuldades de acesso, impedem a realização de diversas atividades turísticas que poderiam 
beneficiar as comunidades locais do entorno das UCs. Em muitas delas, o turismo acontece, mesmo que sem a anuência, controle ou acompanhamento da equipe gestora, como nos casos dos PEBI, MONAT e PNSV, podendo causar impactos negativos ao meio ambiente, como é o caso do PEBI, que recebe cerca de 10.000 turistas no feriado do Carnaval, uma incongruência quando se pensa em conservação da natureza.

No que concerne às características socioeconômicas das comunidades rurais do entorno ou interior dessas UCs, há um consenso de que tratam-se de áreas abandonadas pelo Estado, onde as comunidades foram e continuam sendo excluídas das políticas públicas, dos direitos sociais garantidos em leis, encontrando-se muitas vezes isoladas e enfrentando precárias condições de vida. O acesso aos serviços públicos como saúde, educação, luz, água, esgoto, transporte e vias de acesso são raros e, quando existentes, são de baixa qualidade.

Os moradores dessas comunidades dependem da realização de uma série de atividades para sua subsistência. A agricultura familiar e a pequena pecuária extensiva, com venda de excedentes entre os próprios comunitários e em comércios locais, constituem-se na base da economia da maior parte desta população. A coleta e venda de sempre-vivas e a coleta de espécies vegetais (plantas medicinais, frutos do cerrado, folhas de palmeiras, cipós para cestaria, lenha para fogão à lenha e para construção de casas e móveis, etc) é uma importante atividade que garante uma renda extra para a comunidade, diversifica sua base alimentar e permite menor dependência em relação a produtos vindos das cidades próximas. Além disso, o garimpo artesanal de diamante, ouro e cristal é realizado histórica e culturalmente em toda a região, e possibilita um incremento da renda para muitas famílias. Em alguns casos, foram citados também o comércio, a prestação de serviços e a confecção e venda de produtos artesanais. Destaca-se que os programas assistencialistas e a aposentadoria também se configuram como importante fonte de renda para muitas famílias localizadas nestas áreas.

O sistema grota-chapada, descrito por Ribeiro et al (2011) para o Alto Vale do Jequitinhonha, também é muito comum na região, sendo que as comunidades geralmente estabelecem um tipo de relação com a terra e com os recursos naturais muito peculiar, incorporando na gestão dos recursos suas tradições, técnicas adaptadas e, muitas vezes, práticas sustentáveis. Neste sistema, em geral, as casas e as propriedades privadas estão localizadas nas grotas (encostas de vale), próximo aos cursos d'água e nascentes, local onde plantam as roças e que concentra o trabalho familiar. Nas chapadas (planaltos), estas comunidades soltam o gado na época da seca, e coletam plantas medicinais, semprevivas e frutos, retiram a lenha e caçam para complementar a subsistência das famílias. As 
regras e normas para uso e apropriação dos recursos naturais são estabelecidas por cada comunidade. A afirmação de Ribeiro et. al. (2011) explicita esta prática tradicional:

\begin{abstract}
Nessa região de transição de cerrado para mata atlântica a topografia acidentada das grotas culmina e contrasta vivamente com a planura das chapadas, de vegetação rasteira ou arbustiva e terra "madrasta", que não serve para botar lavouras mas é panacéia para diversas outras necessidades. As grotas, além de boas terras de cultura, têm abundância de água e algumas áreas de matas. Cada grota, com seu entorno de chapadas, abrigou a rede extensa de parentesco que foi compartilhando a vida e o domínio da terra, e é essa junção de família com história e terra que é conhecida por comunidade rural, quase sempre batizada com o nome do córrego que a irriga ou do primeiro morador do lugar (RIBEIRO et. al., 2011, p.8).
\end{abstract}

Muitos projetos do Estado ou de iniciativa privada destroem essa lógica, por não reconhecerem outros sistemas de produção senão o baseado na propriedade privada. Ignorando esses usos tradicionais e as regras de direito costumeiro, vários projetos de monocultura de eucalipto, mineração e construção de barragens hidrelétricas tem sido implantados no alto Vale do Jequitinhonha, em geral, e nesta região em especial, comprometendo a reprodução social das famílias e sua subsistência e destruindo o sistema de uso comum, tradicional na região. Tais conflitos são gerados pelo desconhecimento ou descumprimento das normas locais, pelos agentes hegemônicos, e pela ganância que rege a cultura mercantil. Além desses processos relacionados ao avanço do capital, tais comunidades ainda têm sofrido com o cerceamento de muitas atividades pela implantação de Unidades de Conservação de proteção integral em seus territórios de uso tradicional.

Em função das características descritas acima, a maior parte das populações das zonas rurais do entorno das UCs aqui analisadas se caracterizam como comunidades tradicionais visto que estabelecem estreita relação com os recursos naturais dos quais dependem para sua sobrevivência, possuem grande dependência dos ciclos naturais e criam normas e regras próprias para uso e apropriação comum do território. A definição legal para o termo Povos e Comunidades Tradicionais é a seguinte:

Grupos culturalmente diferenciados e que se reconhecem como tais, que possuem formas próprias de organização social, que ocupam e usam territórios e recursos naturais como condição para sua reprodução cultural, social, religiosa, ancestral e econômica, utilizando conhecimentos, inovações e práticas gerados e transmitidos pela tradição (BRASIL, Decreto $\mathrm{n}^{\circ}$ 6.040, 2007, Art. $3^{\circ}$, item 1).

A Comissão Nacional de Desenvolvimento Sustentável dos Povos e Comunidades Tradicionais reconhece 27 categorias de Povos e Comunidades Tradicionais no Brasil, sendo que dentre elas vale citar as existentes na região analisada, que são comunidades quilombolas e apanhadores de flores sempre-vivas. 
As comunidades certificadas como quilombolas pela Fundação Cultural Palmares, presentes na região são: Comunidade Quilombola Mata dos Crioulos, Vargem do Inhaí, Quartel do Indaiá, Baú, Ausente, Vila Nova e Santa Cruz. Todas elas estão localizadas no interior ou entorno de UCs, sendo a primeira entre o PERP e o PEPI e as duas subseqüentes no entorno do PNSV e as últimas no interior da APA das Águas Vertentes e próximas ao MONAT Várzea do Lajeado e Serra do Raio. Estas comunidades tradicionais (principalmente as três primeiras) têm sofrido com a restrição de uma série de atividades tradicionalmente desenvolvidas por estes grupos, em função da criação das UCs e das novas regras de uso do território, que ignoram os usos tradicionais que ali ocorrem e que, em tese, garantiram a conservação da área antes da criação das UCs.

Os apanhadores de sempre-vivas estão dispersos por toda a porção meridional da Serra do Espinhaço, sendo que além da sobrevivência econômica, esta atividade está fortemente vinculada à identidade cultural dessas comunidades. De acordo com a Comissão Nacional de Desenvolvimento Sustentável dos Povos e Comunidades Tradicionais:

\begin{abstract}
Essa autoidentificação está vinculada à atividade de coleta de flores secas nativas do Cerrado brasileiro que realizam em seus territórios e, ao mesmo tempo, refere-se como uma unidade de ação política na luta pelo reconhecimento de suas práticas e direito de uso de seu território, com o qual mantém vínculos e tradições, muitos destes ligados a práticas quilombolas, dos quais descendem. Além da coleta das flores, as comunidades também realizam outras atividades produtivas que garantam a complementação de renda e a garantia da sua segurança econômica e alimentar, como roças, criação de animais, caça e coleta. (COMISSÃO NACIONAL DE DESENVOLVIMENTO SUSTENTÁVEL DOS POVOS E COMUNIDADES TRADICIONAIS, 2014).
\end{abstract}

Tanto as comunidades quilombolas como os apanhadores de flores sempre-vivas sentem-se cerceados pela criação das UCs na região em função da proibição da coleta de sempre-vivas e de outras espécies vegetais, da soltura de gado de forma comunal que eram realizados em áreas no interior das UCs, e do garimpo artesanal realizado anteriormente em áreas do interior e entorno das UCs. Tal fato tem gerado conflitos entre as comunidades e os órgãos gestores das Unidades de Conservação, tendo sido instituída mesas de diálogo e negociação a fim de solucionar tais conflitos, na tentativa de se estabelecer um Termo de Compromisso entre as comunidades quilombolas e os órgãos gestores das UCs para o uso tradicional e sustentável das sempre-vivas no interior do Parque Nacional das Sempre Vivas e do Parque Estadual do Rio Preto.

Vale destacar, ainda, que foi elaborada e enviada para Brasília uma proposta de recategorização do Parque Nacional das Sempre-Vivas para se tornar uma Reserva de Desenvolvimento Sustentável, dado os diversos usos tradicionais que ali acontecem por estas comunidades tradicionais. Desta forma, o termo de compromisso supracitado valeria até que a situação seja concluída e que a recategorização seja, eventualmente, aprovada. 
Ressalta-se que as perdas para biodiversidade em casos de redução de limites e recategorização de UCs podem ultrapassar os efeitos simples do uso por comunidades tradicionais. A região aqui analisada é alvo constante de tentativas de implantação de projetos minerários e de monocultura de eucalipto, que podem vingar, caso a proteção por Unidades de Conservação de proteção integral deixem de existir, podendo trazer degradação ambiental e prejuízos ainda maiores, para as comunidades tradicionais e para as UCs.

Deve-se enfatizar ainda que a criação de UCs obedece a uma lógica contrária a do capital e que a proteção/preservação da biodiversidade, diante da lógica hegemônica, é tão indefesa quanto as populações tradicionais. Assim, ressalta-se o lado perverso desse conflito socioambiental no qual dois lados, que originalmente foram ou deveriam ser aliados (UCs e povos e comunidades tradicionais) na conservação dos recursos naturais, lutam e se enfraquecem mutuamente, enquanto os interesses de grandes empresas só têm aumentado (mineradoras e monocultura de eucalipto, no caso da área dessa pesquisa). Desta forma, estes dois agentes deveriam estar, sempre, do mesmo lado da balança quando a questão for "enfrentar" os subterfúgios que levam a desafetações, recategorizações, etc.

Vale citar ainda que a Lei que institui o SNUC tramitou no Congresso Nacional por mais de dez anos até ser aprovada e um dos motivos foi a polêmica em torno do conceito de Povos e Comunidades Tradicionais. Por fim, a lei foi aprovada vetando-se o artigo que traria o conceito de populações tradicionais, que seria o seguinte:

Grupos humanos culturalmente diferenciados, vivendo há, no mínimo, três gerações em um determinado ecossistema, historicamente reproduzindo seu modo de vida, em estreita dependência do meio natural para sua subsistência e utilizando os recursos naturais de forma sustentável. (Mensagem nº67, Art 2², 2000).

Os motivos do veto circulam em torno da falta de clareza sobre o fator temporal, sobre o que seria a utilização de recursos naturais de forma sustentável e a possibilidade de inserção neste conceito de grande parte da população rural brasileira. Com base nestes argumentos, as elites brasileiras evitaram grandes discussões sobre os direitos dos povos e comunidades tradicionais e sobre a presença humana em unidades de conservação.

Infelizmente, em função desse veto e de não se encarar o problema naquele momento é que hoje existe um número enorme de conflitos entre unidades de conservação e comunidades tradicionais. Se no início estes conceitos e territórios tinham objetivos convergentes, qual seja, proteger a biodiversidade e a sociodiversidade brasileira, na prática os objetivos foram se afastando e as divergências foram acirradas. Daí o surgimento da "epidemia" de desafetação, recategorização e redução de limites que estamos acompanhando no presente momento e que pode se estender para o futuro, com consequências ambientais inimagináveis. 


\section{RECATEGORIZAÇÃO, DESAFETAÇÃO E REDUÇÃO DE LIMITES DE UCS E 0 ENFRAQUECIMENTO DO SNUC}

As análises apresentadas neste sub-ítem tiveram por base uma extensa revisão bibliográfica e de sobre processos de recategorização, desafetação e redução de limites de UCs, principalmente baseada em MASCIA et al (2014), ORTIZ (2013) e SOUZA, STUMPF \& ZANCHET (2015). Além disso, foram analisados textos legais e processos em cursos que tentam enfraquecer o SNUC e os instrumentos de implantação de UCs, tais como a Constituição Federal de 1988, a Lei n 9985/2000, o projeto de lei n 3.682/2012, a PEC 215/2000 da Câmara e a PEC 72/2011 do Senado

A revisão dos limites de uma UC, sua recategorização ou sua extinção integral podem ocorrer por diversos motivos, sejam eles políticos, econômicos, sociais, culturais ou ambientais. Esta prática tem se tornado cada vez mais constante, seja em nível municipal, estadual ou federal, em função de conflitos e/ou jogos de interesses diversos.

A redefinição de limites pode ser conduzida pelo órgão gestor da UC, visando incluir áreas de maior relevância ecológica e excluir outras que não possuam atributos que justifiquem sua inserção no contexto da UC, ou para corrigir imperfeições de seu desenho inicial (como ocorreu com a APA das Águas Vertentes e com os Parques Estaduais do Pico do Itambé e do Rio Preto, que tiveram seus limites ampliados após sua criação). Porém, na grande maioria das vezes, esta redefinição de limites, a recategorização ou desafetação de UCs ocorrem em função de pressões externas para o desenvolvimento de atividades em escala industrial, principalmente relacionadas a projetos mineradores, agronegócio, monocultura de eucalipto e implantação de infraestrutura (principalmente rodovias e hidrelétricas).

Estudos recentes realizados nacional e internacionalmente revelam dados impressionantes sobre estes processos de desafetação, recategorização e redefinição de limites de UCs, que aqui estamos nomeando de "epidemia". Em recente levantamento realizado pelo Ministério do Meio Ambiente, foram identificados mais de 400 projetos de lei em tramitação no Congresso que tentam redefinir os limites de UCs (ORTIZ, 2013).

Além disso, nos últimos anos, cerca de 5,2 milhões de hectares perderam o status de proteção ambiental em função de desafetação ou redefinição de limites de UCs, segundo pesquisa publicada na revista Biological Conservation, sendo que o fato se intensificou entre os anos de 2008 e 2012. Segundo este artigo (Protected area downgrading, downsizing, and degazettement (PADDD) in Africa, Asia, and Latin America and the Caribbean, 1900-2010), este não é um fato que está ocorrendo apenas no Brasil, tendo sido identificados 543 casos de recategorização, redefinição de limites ou desafetação em 375 áreas protegidas, em 57 
países dos continentes pesquisados. Segundo o artigo, as causas são diversas, mas estão primariamente centradas no acesso e uso dos recursos naturais, em particular para a extração de recursos e o desenvolvimento de projetos em escala industrial (tais como mineração, óleo e gás, agricultura e a construção de infraestruturas) (MASCIA et. al., 2014, p. 357).

Estas análises desconstroem a noção amplamente divulgada de que as áreas protegidas estão constantemente aumentando em número e área de abrangência, e que uma vez criadas, estas áreas garantem permanentemente a proteção da biodiversidade. Esta visão é apontada no Protected Planet Report 2016 (Relatório sobre o Planeta Protegido, elaborado pelo Programa das Nações Unidas para o Meio Ambiente) que relata o seguinte:

Nos últimos 20 anos, tem havido um aumento dramático no número e extensão de áreas protegidas estabelecidas globalmente, representando um crescente reconhecimento do valor da proteção como uma forma de salvaguardar a natureza e os recursos culturais e mitigar os impactos humanos sobre a biodiversidade. ${ }^{2}$ (UNITED NATIONS ENVIRONMENT PROGRAMME, 2016, p. 1).

O Brasil possui atualmente cerca de 2.029 UCs cadastradas no Ministério do Meio Ambiente, cobrindo uma área de cerca de $1.544 .833 \mathrm{~km}^{2}$, que representa cerca de $17 \%$ do território nacional (CNUC, 2016), atingindo as metas da Convenção da Biodiversidade e de Aichi, que determinam que $17 \%$ de todo o planeta deve ser protegido até 2020 . Porém, apesar dos avanços e dos números impressionantes, existe uma grande necessidade de melhoria da qualidade dessas UCs que, em sua imensa maioria, ainda não estão efetivamente implantadas e apresentam diversos problemas, ameaças, lacunas e fragilidades, como: situação fundiária irregular, precariedade de recursos humanos e financeiros, falta de infraestrutura e equipamentos, ausência de plano de manejo ou planos de manejo desatualizados, falta de envolvimento com as comunidades locais, entre outros. Este é o caso também das UCs analisadas no item anterior. Além disso, destaca-se que grande parte desses $17 \%$ do território nacional coberto por UCs está concentrada na região Amazônica, cuja lógica de pressão espacial é bastante diferente do restante do território nacional, e que também vem sofrendo bastante com processos de desafetação, recategorização e redução de limites de UCs.

\footnotetext{
Over the past 20 years, there has been a dramatic increase in the number and extent of protected areas established globally, representing a growing ecognition of the value of protection as a way to safeguard nature and cultural resources and mitigate human impacts on biodiversity. (tradução do autor)
} 
Em função dessas ameaças crescentes às UCs brasileiras, foi reeditada no Brasil, em 2014, a Rede Nacional Pró Unidades de Conservação ${ }^{3}$ visando fortalecer a cooperação entre os atores que trabalham em prol das causas ambientais e cobrar dos governantes posturas que garantam a perpetuidade e o adequado gerenciamento das UCs no país. Neste sentido, foi estabelecida uma agenda mínima para as UCs, para os anos de 2015 a 2018, sendo que entre as ações está:

Estabelecer e orientar um processo de análise técnica transparente e consulta pública para avaliar a real relevância de redução, recategorização e desafetação de unidades de conservação. Nos casos extremos em que as alterações são inevitáveis, deve-se estabelecer um processo de compensação das perdas a partir da ampliação das UCs ou criação de novas, garantindo a representatividade do sistema e proteção de áreas com biodiversidade equivalente (REDE NACIONAL PRÓ-UNIDADES DE CONSERVAÇÃO, 2014).

Desta forma, é necessário estabelecer diretrizes técnicas para esse tipo de procedimento (recategorização, desafetação e redução de limites), estabelecendo regras e garantias legais para que os interesses e pressões dos setores econômicos e desenvolvimentistas não sejam sobrepostos às necessidades de conservação e proteção da biodiversidade, e às demandas dos povos e comunidades tradicionais.

Percebe-se atualmente que, mesmo havendo garantias legais e constitucionais para a criação e implementação de UCs, quando o interesse econômico é grande, a tendência é de que haja diminuição de sua área, alteração de categoria e/ou desafetação de UCs. O lobby pressionando as UCs brasileiras se intensificou durante o mandato da ex-presidente Dilma Rousself, com edição de Medidas Provisórias para redução de limites de UCs na Amazônia e sem estudos técnicos que justificassem tal redução, em desacordo com o que prevê o SNUC. A Constituição Federal prevê que “[...] a alteração e a supressão [serão] permitidas somente através de lei, vedada qualquer utilização que comprometa a integridade dos atributos que justifiquem sua proteção" (Constituição Federal, 1998, art. 225, §1 1 , III). Além disso, a Lei $n^{\circ} 9985 / 2000$, em seu art. 22, $\$ 7^{\circ}$, prevê expressamente que a desafetação ou redução dos limites - que é o caso das MPs 542/2011 $1^{4}$ e 558/2012 5 - de uma UC só pode ser feita mediante lei específica. Exceção é dada para casos em que se aumente o grau de proteção da UC ou ainda em que se pretenda acrescentar territórios à UC sem mudança

\footnotetext{
"A Rede Pró Unidades de Conservação é uma organização não governamental, portanto sem fins lucrativos, que atua na defesa direta das unidades de conservação do Brasil, especialmente aquelas de proteção integral. Foi criada a 16 anos, e na época um dos principais objetivos era acompanhar o trâmite legislativo e influenciar positivamente a Lei do Sistema Nacional de Unidades de Conservação (SNUC), que foi promulgada em julho de 2000 como a Lei 9.985." (KUCZACH, 2014)

${ }^{4}$ Previa a redução da área de três Parques Nacionais na Amazônia: O Parque Nacional dos Campos Amazônicos, o Parque Nacional da Amazônia e o Parque Nacional Mapinguari,

5 Previa a redução da área de sete UCs na Amazônia, em mais de cem mil hectares, posteriormente convertida para a Lei $\mathrm{n}^{\circ} 12.678 / 2012$.
} 
nos demais limites originais, sendo possível, nestes casos, realizar tais mudanças por meio do mesmo instrumento de criação das UC (decreto ou portaria).

O manual de apoio à atuação do Ministério Público sobre criação, implantação e gestão de unidades de conservação vai ainda mais longe ao analisar os textos legais no que se refere à desafetação de UCs com situação fundiária ainda irregular, e argumenta o seguinte:

\begin{abstract}
Casos de desafetação ensejam que a posse e o domínio sejam públicos. A desafetação é entendida como o ato que subtrai o bem do domínio público para integrá-lo ao patrimônio privado, diferentemente da redução de limites, bem mais simples, uma vez que pode ocorrer mesmo nos casos em que a UC não esteja com sua regularização fundiária efetivada, ou seja, ainda sob o domínio do particular. (SOUZA, STUMPF \& ZANCHET, 2015, p.54).
\end{abstract}

Desta forma, fica claro que desafetação, redução de limites ou recategorização para UC de menor proteção só podem ser realizados por meio de Lei específica, devendo basear-se em estudos técnicos coordenados pelo órgão gestor da UC, com participação da sociedade, da comunidade científica e da população local, e se forem realizadas em UCs com situação fundiária regular (para casos de desafetação).

Outra questão que tem ameaçado as UCs brasileiras refere-se às diversas tentativas de flexibilização e enfraquecimento da Lei do SNUC que atualmente tramitam no Congresso Nacional. O projeto de lei $n^{\circ} 3.682 / 2012$ tem por objetivo permitir que até $10 \%$ das UCs de Proteção Integral possam ser utilizadas para mineração e tenta transferir do Poder Executivo para o Congresso o poder de criar ou não UCs. O projeto de lei ainda tenta impedir de serem criadas UCs em áreas de favorabilidade geológica para mineração e com recursos hídricos estratégicos para a geração de energia elétrica. Este projeto de lei pretende ainda modificar o SNUC no que se refere ao instrumento legal para reduzir os limites ou diminuir a categoria de proteção de UC, que até então deve ser feito por meio de Lei específica e que, com a nova redação, passaria a ser feito por Decreto Presidencial.

Outro exemplo são as Propostas de Emendas Constitucionais (PEC 215/2000 da Câmara e a PEC 72/2011 do Senado) que propõem alterar a Constituição para retirar do poder executivo a decisão final de criar e extinguir Unidades de Conservação, Terras Indígenas e Territórios Quilombolas, transferindo tal responsabilidade para o Congresso Nacional, que possui lideranças e representação majoritária de interesses de grandes empresas, mineradoras e ruralistas. Além de defender interesses setoriais, a Câmara e o Senado não possuem corpo técnico especializado (como há no Poder Executivo) para decidir sobre a criação e extinção dessas áreas protegidas. 


\section{A NECESSIDADE DE FLEXIBILIZAÇÃO DA GESTÃO DE UCS DE PROTEÇÃO INTEGRAL RELACIONADA AO USO POR COMUNIDADES TRADICIONAIS}

Neste sub-ítem apontaremos para a necessidade de flexibilização da proteção integral quando se tratam de usos realizados por comunidades tradicionais, utilizando as UCs da porção central do Mosaico do Espinhaço como estudos de caso, que apontaram para a necessidade de discussões mais ampla sobre desafetação e recategorização em unidades de conservação de proteção integral. Estas análises baseiam-se no cenário atual de sucateamento das UCs, como apresentado anteriormente neste artigo, na realidade apresentada anteriormente sobre a "epidemia" de processos de recategorização, desafetação e redução de limites de UCs no Brasil e em outros países e nas discussões teóricas sobre os instrumentos que permitem tal flexibilização (SATHLER, 2010; MINISTÉRIO PÚBLICO FEDERAL, 2014 e ICMBIO, 2012). Além disso, as percepções empíricas dos autores, tendo em vista pesquisas anteriormente desenvolvidas na área em questão ${ }^{6} \mathrm{o}$ acompanhamento das discussões em curso sobre comunidades tradicionais e UCs do Mosaico do Espinhaço possibilitaram uma analise mais aprofundada desta realidade.

Primeiramente, é necessário enfatizar a importância das áreas protegidas para a proteção da biodiversidade, para garantia dos recursos naturais e ainda para sustentar as necessidades da sociedade humana por meio dos serviços ambientais prestados. Além disso, ressalta-se que tais áreas são essenciais para as culturas e meios de subsistência das comunidades locais e dos povos e comunidades tradicionais.

Porém, o que se verifica nos últimos anos é uma desestabilização das UCs, tornandoas suscetíveis a novas alterações na categoria de proteção e em seu tamanho, geralmente com o intuito de atender interesses econômicos. Tais mudanças têm diminuído a proteção da biodiversidade brasileira e contribuído para um enfraquecimento das políticas de conservação da natureza, como apresentado no item anterior.

Evandro Sathler, ao analisar as UCs do Rio de Janeiro, conceituou-as como espaços de incertezas jurídicas, que, de acordo com o autor, são as áreas previamente ocupadas ou utilizadas por posseiros/proprietários, e que passam a integrar os limites de uma Unidade de Conservação de Proteção Integral, impondo às comunidades locais restrições legais que inviabilizam sua utilização econômica ou costumeira (SATHLER, 2010). Estas incertezas recaem sobre as comunidades, que dependiam dos recursos naturais do interior das UCs para sua sobrevivência e para a reprodução de suas práticas sociais; e também do ponto

6 Como exemplo, podemos citar algumas pesquisas desenvolvidas pelos autores: SOUZA, SCALCO e XAVIER (2012); MOTTA et al (2014); LIMA, SCALCO e VARAJÃO (2015); SCALCO e SOUZA (2016); SCALCO e GONTIJO (2016); GONTIJO (2008); RIBAS e GONTIJO (2015); MORAIS et al (2013), GONTIJO (2016). 
de vista administrativo, pois já não há mais garantias de que uma área instituída como UC, garanta permanentemente a proteção da biodiversidade, haja vista a "epidemia" de processos de recategorização, desafetação ou redução dos limites de UCs em função de interesses do capital. Sob o ponto de vista do autor, é necessário um pacto da conservação, visando diminuir as incertezas que recaem tanto sobre as comunidades, como sobre os órgãos ambientais em função dos inúmeros conflitos existentes neste ínterim.

Além dessas incertezas, destaca-se o fato de as UCs não estarem efetivamente implantadas e os diversos problemas enfrentados (alguns já expostos anteriormente), enfatizando o quanto estas áreas estão ameaçadas, a despeito de estarem legalmente criadas e, em teoria, amparadas pela Constituição e pela Lei do SNUC. A colocação de Ângela Kuczach corrobora com esta afirmação:

\begin{abstract}
No que se refere às unidades de conservação o que se nota é a falta absoluta de planejamento e investimento de longo prazo. A maior parte do território das UCs não está regularizado, mesmo quando pertence de fato a união não está discriminado e titulado, o que por si só é uma ameaça enorme! A falta de pessoal é gritante e a capacitação, em geral deixa a desejar. Também, como já dito, não há investimento suficiente, na verdade nem o minimamente essencial. O Ministério do Meio Ambiente, que responde pela gestão das UCs federais têm hoje o segundo menor orçamento entre os ministérios e isso tendo de administrar mais de 75 milhões de hectares em UCs, território maior que o Paraguai e Uruguai somados. Em 2014 o recurso investido para a gestão de toda essa área é de pouco mais de $\mathrm{R} \$ 400$ milhões, o que dá cerca de $\mathrm{R} \$ 8$ por hectare. Claro que com isso faltam recursos para estrutura, fiscalização, manejo (KUCZACH, 2014).
\end{abstract}

Observa-se, assim, um descaso do poder público com o SNUC, com poucas UCs sendo criadas nos últimos anos, cortes de verbas, pressão no Congresso para desafetar, recategorizar e reduzir limites e propostas de alteração da lei do SNUC, na tentativa de enfraquecê-lo perante os interesses do capital. Neste cenário, o que se visualiza é um enfraquecimento das políticas ambientais brasileiras, a prevalência da visão do meio ambiente como um entrave ao desenvolvimento e o modelo de apropriação da natureza baseado no capital.

Estes problemas acima citados ameaçam também as UCs da área central do Mosaico do Espinhaço, foco de análise deste trabalho. A escassez de recursos humanos e financeiros, planos de manejo desatualizados, precariedade da infraestrutura, entre outros fatores, são problemas enfrentados pela grande maioria delas, como já apontado neste artigo. Além disso, existem processos em curso que podem diminuir o status de proteção com possibilidade de recategorização (no caso do Parque Nacional das Sempre-Vivas) e de redução de limites (no caso dos Parques Estaduais do Rio Preto e Pico do Itambé), todos relacionados com usos anteriores por comunidades tradicionais. 
Sendo assim, percebe-se uma necessidade enorme de se estabelecer parcerias com as comunidades locais, enxergá-las como potenciais parceiras na conservação dos recursos naturais e criar uma postura mais conciliatória no tocante à presença humana em UC de proteção integral, seja permanente, seja sazonal, principalmente quando se tratam de comunidades tradicionais. Isso, posto que desafetar, reduzir limites ou recategorizar enseja danos ainda maiores à proteção dos recursos naturais, visto que diversos setores econômicos (mineradoras, hidrelétricas, agropecuária, silvicultura) têm interesses imensos nas mudanças acima mencionadas e utilizam-se desses conflitos para se beneficiarem da diminuição do status de proteção de UCs.

Esta necessidade é ainda maior quando se tratam de áreas de grande valor ecológico, prioritárias para a conservação da biodiversidade e que ainda encontram-se bastante conservadas, como é o caso das UCs da porção central do Mosaico do Espinhaço. Além disso, as comunidades do entorno destas UCs, como apontado anteriormente, conviveram durante várias gerações de forma relativamente harmônica com a natureza, dependendo dos recursos naturais para sua sobrevivência e para a reprodução de suas práticas sociais e possuindo formas de utilização desses recursos diferentes da sociedade hegemônica. Assim, a flexibilização da proteção integral, na prática, seria uma forma de perder menos no jogo de forças.

Além disso, destaca-se que a maior parte, se não todas, as comunidades rurais dessa região têm sido constantemente visitadas por empresas mineradoras interessadas em pesquisa e exploração de quartzito, e em alguns locais elas já iniciaram seu processo de implantação, como no entorno do PNSV (comunidade de Santa Rita) e do PEPI (Capivari). Projetos de monocultura de eucalipto também estão presentes em várias áreas no entorno das UCs da área central do Mosaico do Espinhaço, como por exemplo no entorno do PERP e do PNSV. Sendo assim, a diminuição do status de proteção, a redução de limites ou a desafetação de Unidades de Conservação nesta região podem significar não a vitória dos povos e comunidades tradicionais que lutam pelo uso sustentável dos recursos naturais no interior e entorno das UCs, mas uma possibilidade de implantação de grandes projetos mineradores e de reflorestamento de eucalipto, trazendo degradação ambiental e prejuízos ainda maiores tanto para as comunidades tradicionais como para o meio ambiente.

Caso o Parque Nacional das Sempre-Vivas seja recategorizado, ou tiver seus limites reduzidos, em função do uso por apanhadores de flores sempre-vivas, ou em função da titulação das terras das comunidades quilombolas Vargem do Inhaí e Quartel do Indaiá as perdas para a biodiversidade e para a proteção dos recursos naturais serão enormes. Isso porque esta é a maior UC do Mosaico do Espinhaço, abrigando importantes nascentes 
(cerca de 600, segundo seu plano de manejo) e cursos d'água, espécies endêmicas e algumas ameaçadas de extinção (ICMBIO, 2016), além de espécies novas, recentemente descobertas por projeto de pesquisa da UFVJM.

Pondera-se que esta proposta de recategorização é interessante, principalmente porque parte de um pleito de membros das comunidades. Porém, deve ser feito um estudo detalhado de quais áreas devem ser recategorizada, pois não é toda a área do Parque que é ou foi utilizada pelas comunidades tradicionais de seu entorno. Além disso, há que se levar em consideração os diversos interesses econômicos incidentes sobre a área, como já ressaltado anteriormente. Assim, caso a proposta de recategorização vá para o Congresso Nacional, para ser analisada e votada por seus membros, na maioria de bancadas ruralistas e/ou defendendo interesses setoriais, os riscos são enormes, inclusive de desafetação total da área, caso exista conchavos políticos interessados no assunto.

Já para o Parque Estadual do Rio Preto, caso este perca parte de sua área em função da titulação das terras da comunidade quilombola Mata dos Crioulos, as perdas podem ser grandes, já que a área pleiteada representa cerca de um quarto da área do Parque e é exatamente onde estão as principais nascentes do Rio Preto, principal atributo que justificou a criação do Parque. Trata-se de uma área de campos hidromórficos, bastante frágil do ponto de vista ambiental e que, a depender da eventual pressão de uso por parte da comunidade da Mata dos Crioulos, pode prejudicar toda a bacia hidrográfica do Rio Preto, o abastecimento de água do município de São Gonçalo do Rio Preto e ainda os usos turísticos e recreativos do rio e do Parque.

Assim, a percepção empírica dos autores (tento em vista a robusta reflexão teórica aqui apresentada, bem como o cenário atual de sucateamento das UCs e cortes sucessivos no INCRA para regularização fundiária de territórios quilombolas ${ }^{7}$ ) é que a dupla-afetação, para os casos de territórios quilombolas sobrepostos à UCs de proteção integral seja o caminho mais viável, tanto para os órgãos gestores, como para a comunidade, como ainda para garantir a proteção da biodiversidade.

No caso do Parque Nacional das Sempre Vivas, para os apanhadores de flores semprevivas o pleito é a recategorização para RDS. Destaca-se, porém, que não é toda a extensão do Parque que é utilizada pelas comunidades tradicionais e, assim, a regategorização poderia não incidir em toda a área do Parque. Porém, outro caminho já apontado pela equipe

Em sete anos, o orçamento do Incra apresentou uma queda de 94\%. Para 2017, o órgão dispõe de apenas R 4 milhões para encaminhar mais de 1.600 processos de titulação. [...] As limitações orçamentárias das Superintendências (Superintendências Regionais do INCRA) representam um sério gargalo para a continuidade da maior parte dos processos, já que $87 \%$ dos 1.675 processos não tiveram o Relatório Técnico de Identificação e Delimitação (RTID) publicado (COMISSÃO PRÓ-INDIO DE SÃO PAULO, 2017). 
gestora e pelo Ministério Público Federal e Estadual é o estabelecimento do Termo de Compromisso, que algumas comunidades vêm se negando a fazer. No caso dos territórios quilombolas, a dupla-afetação poderá ser implementada, já que os objetivos podem ser conciliados por meio de acordos e termos de compromisso.

No caso do Parque Estadual do Rio Preto, parte-se da hipótese de que, por meio da conciliação de interesses e da gestão participativa, possa ser implementada a dupla afetação, ou seja, a área utilizada pelos quilombolas para sua reprodução social não inviabiliza a presença das UCs, desde que haja o estabelecimento de critérios e normas para a utilização dos recursos naturais.

No caso de não haver possibilidade de conciliação e dupla afetação da área, há uma tendência para a preponderância dos interesses das comunidades tradicionais, sendo o direito coletivo dos quilombolas considerado superior ao direito difuso ao meio ambiente equilibrado (CHACPE, 2014). Desta forma, poderá ocorrer a desafetação de parte das UCs sobrepostas aos territórios quilombolas a serem titulados, o que traria grandes prejuízos às UCs.

Destaca-se que a desafetação de parte ou de toda uma unidade de conservação para ser reconhecida apenas como território quilombola nem sempre é interessante, pois pode aumentar a vulnerabilidade da comunidade quilombola a outros fatores externos, principalmente aqueles vinculados às forças do capital, relacionados à pressão imobiliária, mineradoras, fazendeiros e outros agentes econômicos, dependendo da capacidade de governança da comunidade para a gestão de seu território (BRASIL, MINISTÉRIO PÚBLICO FEDERAL, 2014, p.106).

Existem na região central do Mosaico do Espinhaço diversos pedidos de licença para pesquisa e exploração minerária de quartzito para fins ornamentais, sendo que no entorno de várias UCs da região já foram identificados testes com dinamite para verificar a qualidade do quartzito que ali se encontra. Além disso, empresas de plantio de eucalipto também têm interesse na região e já tentaram se implantar próximo à Vargem do Inhaí (entorno do PARNA Sempre-Vivas) e já existem plantações em outras regiões no entorno do PNSV e nos limites do PERP. Assim, a vulnerabilidade desses territórios tenderia a aumentar se tais processos forem levados a curso e caso haja redefinição de limites e/ou recategorização das UCs em tela.

A pesquisa publicada na Revista Científica Biological Conservation sugere que outras formas de gestão dos recursos naturais, como terras indígenas e sistemas de gestão de base comunitária, podem conservar a biodiversidade de forma mais eficaz e permanente do que as próprias áreas protegidas. 
Desta forma, a percepção dos autores é de que o melhor caminho para a solução dos conflitos advindos do uso de recursos naturais de UCs de proteção integral por povos e comunidades tradicionais é por meio da flexibilização da proteção integral, na tentativa de conciliar objetivos aparentemente divergentes, estabelecendo parcerias na luta contra um inimigo muito mais forte, qual seja, aquele relacionado ao avanço do capital e a "projetos desenvolvimentistas" que podem causar grandes danos ao meio ambiente, em áreas desafetadas por antigas UCs. Assim, os pactos para a conservação (SATHLER, 2010), o estabelecimento de termos de compromisso, normas para o uso dos recursos por comunidades tradicionais ou o próprio zoneamento da UC podem ser instrumentos muito mais interessante, tanto para comunidades tradicionais como para órgãos gestores de UCs. Isso posto que levar a cabo processos de recategorização ou redefinição de limites das UCs de Proteção Integral antagonizam dois lados mais fracos, quando se considera as forças e interesses hegemônicos do capital, tal como vem ocorrendo na porção central do Mosaico do Espinhaço.

\section{CONSIDERAÇÕES FINAIS}

Este estudo se justifica tendo por base uma questão muito polêmica e que tem gerado muito conflito: a presença humana nas unidades de conservação de proteção integral. A origem desses conflitos é justamente o domínio e a responsabilidade sobre a área e os recursos naturais nela contidos. Se, por um lado, os órgãos gestores das UCs tem o interesse no não-uso da terra, para garantir a preservação da mesma; por outro, as comunidades tradicionais necessitam destes mesmos recursos para sua existência enquanto grupos sociais diferenciados. Estes conflitos têm gerado uma série de processos que podem culminar na redefinição de limites ou recategorização de UCs, diminuindo e vulnerabilizando a proteção da biodiversidade e dos recursos naturais associados. Nesse sentido, o presente artigo atinge o objetivo a que se propôs, qual seja, o de refletir sobre a necessidade de flexibilização da proteção integral quando se tratam de usos feitos por comunidades tradicionais para evitar perdas maiores advindas de processos de recategorização, redefinição de limites e desafetação de áreas de UCs. Para se chegar a esta análise, foi utilizado como estudo de caso as UCs da porção central do Mosaico do Espinhaço, discutindo-se sobre os conflitos entre órgãos gestores de UCs e comunidades tradicionais presentes na área em tela.

Assim, fica a reflexão sobre a necessidade de se compatibilizar interesses sociais e ambientais, de modo a repensar a histórica separação entre sociedade e natureza. Considerando este antagonismo, as unidades de conservação no Brasil foram concebidas, 
criadas e geridas como ilhas de conservação (seguindo o modelo norte-americano de parques), tentando-se excluir todas as possibilidades de alteração do ambiente causadas por populações residentes, tradicionais ou não.

No caso brasileiro, especialmente no território extra-amazônico, muito raramente se têm UCs onde população e natureza não estejam indissociadas, principalmente na região analisada neste estudo. Sendo assim, a análise e solução de conflitos advindos do uso de áreas de UC de proteção integral por comunidades tradicionais devem considerar, sempre, a complexidade desta questão e a possibilidade de conciliação.

Destaca-se, por fim, que as comunidades tradicionais, além de serem corresponsáveis pela conservação das áreas das UCs antes da criação das mesmas, possuem usos de recursos naturais, em tese, compatíveis com os objetivos do SNUC. Assim, as associações representantes de comunidades quilombolas e dos apanhadores de flores sempre-vivas, juntamente com órgãos gestores de UCs poderiam se unir para lutar contra outros atores que realmente vão contra os objetivos de conservação da natureza, como o avanço das fronteiras agrícolas, as mineradoras, a monocultura de eucalipto, a especulação imobiliária e outros fenômenos característicos da nossa sociedade urbano-industrial.

\section{REFERÊNCIAS}

1. ABREU, Manuella Muzzi de. Territorialidade e Pertencimento: o olhar local sobre o Parque Estadual do Pico do Itambé, Serra do Espinhaço - MG. Dissertação de Mestrado. Programa de Pós-Graduação em Psicossociologia de Comunidades e Ecologia Social - EICOS. Instituto de Psicologia. Universidade Federal do Rio de Janeiro. Rio de Janeiro, 2015.

2. ÁVILA, Gabriel Carvalho de. Mosaico de áreas protegidas do espinhaço: alto Jequitinhonha e Serra do Cabral, Minas Gerais e os desafios para sua efetividade. Dissertação de mestrado. Programa de Pós-graduação em Geografia. Instituto de Geociências. Universidade Federal de Minas Gerais. Belo Horizonte, 2014.

3. BRASIL. Decreto $\mathbf{n}^{\circ} \mathbf{6 . 0 4 0}$, de 07 de fevereiro de 2007. Institui a Política Nacional de Desenvolvimento Sustentável dos Povos e Comunidades Tradicionais. Brasília, 2007.

4. BRASIL. Lei $\mathbf{n}^{\circ} \mathbf{9 . 9 8 5}$, de $\mathbf{1 8}$ de julho de 2000. Regulamenta o art. 225, parágrafo $1^{\circ}$, incisos I, II, III e VII, da Constituição Federal, institui o Sistema Nacional de Unidades de Conservação e dá outras providências. Brasília, 2000.

5. BRASIL. MINISTÉRIO PÚBLICO FEDERAL. $6^{\circ}$ CÂMARA DE COORDENAÇÃO E REVISÃO. Territórios de povos e comunidades tradicionais e as unidades de conservação de proteção integral: alternativas para o asseguramento de direitos socioambientais / 6. Câmara de Coordenação e Revisão; coordenação Maria Luiza Grabner; redação Eliane Simões, Débora Stucchi. - Brasília: MPF, 2014. 
6. CADASTRO NACIONAL DE UNIDADES DE CONSERVAÇÃO. Tabela Consolidada das Unidades de Conservação. 2016. Disponível em www.mma.gov.br/cadastro_uc Acesso em 23/11/17.

7. CHACPE, Juliana Fernandes. Territórios quilombolas e unidades de conservação de proteção integral: desafios da conciliação na Administração Federal. Dissertação de Mestrado. Centro de Desenvolvimento Sustentável. Universidade de Brasília. Brasília, 2014.

8. COMISSÃO NACIONAL DE DESENVOLVIMENTO SUSTENTÁVEL DOS POVOS E COMUNIDADES TRADICIONAIS. Apanhadores de Sempre-Vivas. 2014. Disponível em: http://portalypade.mma.gov.br/apanhadores-de-sempre-vivas/ Acesso em: 27-10-16.

9. COMISSÃO PRÓ-ÍNDIO DE SÃO PAULO. Direitos ameaçados: orçamento do Incra inviabiliza titulação de terras quilombolas. São Paulo, 2017. Disponível em <http://comissaoproindio. blogspot.com.br/2017/06/direitos-ameacados-orcamento-do-incra.html>. Acesso em: 01/06/2017.

10. CUNHA, Daniel Fontenele Sampaio. Remanescentes de Quilombos e Unidades de Conservação: ontologia de conflitos e o papel do Ministério Público. In. Boletim Científico ESMPU, Brasília, a. 9 - n. 32/33, p. 103-142 - jan./dez. 2010.

11. GONTIJO, Bernardo Machado. Por uma Geografia para a Cadeia do Espinhaço. In. Megadiversidade. Volume 4. No 1-2. Dezembro de 2008.

12. GONTIJO, Bernardo Machado. A Reserva da Biosfera da Serra do Espinhaço (MG): laboratório e Locus privilegiado de pesquisa do fenômeno turístico e suas interfaces com a natureza e a cultura. In. Turismo, natureza e cultura: diálogos interdisciplinares e políticas públicas. IRVING, Marta de Azevedo et al (Org) - Rio de Janeiro: Fundação Casa de Rui Barbosa, 2016.

13. INSTITUTO CHICO MENDES DE CONSERVAÇÃO DA BIODIVERSIDADE. Roteiro Metodológico de Planejamento: Parque Nacional, Reserva Biológica e Estação Ecológica. Brasília, 2011.

14. INSTITUTO CHICO MENDES DE CONSERVAÇÃO DA BIODIVERSIDADE. Instrução Normativa $^{\circ}{ }^{26}$, de 4 de julho de 2012. Estabelece diretrizes e regulamenta os procedimentos para a elaboração, implementação e monitoramento de termos de compromisso entre o Instituto Chico Mendes e populações tradicionais residentes em unidades de conservação onde a sua presença não seja admitida ou esteja em desacordo com os instrumentos de gestão. Brasília, 2012.

15. INSTITUTO CHICO MENDES DE CONSERVAÇÃO DA BIODIVERSIDADE. Plano de Manejo do Parque Nacional das Sempre-Vivas. Brasília, 2016.

16. INSTITUTO ESTATUAL DE FLORESTAS. Estudo Técnico para a Criação do Monumento Natural Várzea do Lajeado e Serra do Raio, Município de Serro, Minas Gerais. Belo Horizonte/ MG, 2010.

17. INSTITUTO ESTATUAL DE FLORESTAS. Relatório Anual de Atividades - 2015. Monumento Natural Várzea do Lajeado e Serra do Raio. Serro/MG, 2016.

18. KUCZACH, Ângela. Grupo Promete Ações Judiciais para Salvar Nossos Parques da Extinção. São Paulo, 2014. Entrevista concedida à Revista Época - Blog do Planeta em 21 de março de 2014. Disponível em http://epoca.globo.com/colunas-e-blogs/blog-do-planeta/noticia/2014/03/ para-bsalvar-nossos-parquesb-da-extincao.html Acesso em: 08/02/17. 
19. LIMA, Maíra Cristina de Oliveira; SCALCO, Raquel Faria; VARAJAO, Guilherme Fortes Drummond Chicarino. Estudo Preliminar da Oferta Turística da Área de Proteção Ambiental das Águas Vertentes - MG/Brasil. In: ANJOS, Francisco Antônio; ANGELI, Newton Paulo; FONTANA, Rosislene de Paula. (Org.). Turismo na Natureza. 1ed.Itajaí/SC: Univali Editora, 2015, v. , p. 81-99.

20. MASCIA; Michael B.; PAILLER, Sharon; KRITHIVASAN, Roopa; ROSHCHANKA, Volha; BURNS, David; MLOTHA, McCard Joseph; MURRAY, Dana Roeber; PENG, Naiying. Protected area downgrading, downsizing, and degazettement (PADDD) in Africa, Asia, and Latin America and the Caribbean, 1900-2010. In. Biological Conservation. 169 (2014) 355-361.

21. MENDONÇA, Vinícius Souza. Agrobiodiversidade e o Conhecimento Tradicional na Comunidade Quilombola Mata dos Crioulos. Trabalho de Conclusão de Curso. Curso de Engenharia Florestal. UFVJM. Diamantina, 2013.

22. MONTEIRO, Fernanda Testa. Os(as) Apanhadores(as) de Flores e o Parque Nacional das Sempre-vivas (MG): travessias e contradições ambientais. Dissertação de Mestrado. Programa de Pós-graduação em Geografia. Instituto de Geociências. Universidade Federal de Minas Gerais. Belo Horizonte, 2011.

23. MORAIS, Marcelino Santos de. A Realidade Socioambiental Imposta às Comunidades Locais pela Criação e Implementação dos Parques Estaduais do Biribiri e Rio Preto. Tese de doutorado. Programa de Pós-graduação em Geografia. Instituto de Geociências. Universidade Federal de Minas Gerais. Belo Horizonte, 2014.

24. MORAIS, M. S. ; PIUZANA, D. ; DUPIN, Patrícia C. ; GONTIJO, B. M. . Comunidades e Unidades de Conservação: A realidade dos conflitos entre as comunidades do entorno dos parques estaduais do Rio Preto e Biribiri, MG. Olam: Ciência \& Tecnologia (Rio Claro. Online), v. 13, p. 246-268, 2013.

25. MOTTA, Adeline Isis Rodrigues da; SCALCO, Raquel Faria; VARAJÃO, Guilherme Fortes Drummond Chicarino; SOUZA, Daniella Eloi de. Análise da Oferta Turística da APA Estadual das Águas Vertentes. Relatório de Bolsa de Iniciação Científica. Curso de Turismo. Faculdade Interdisciplinar em Humanidades. Universidade Federal dos Vales do Jequitinhonha e Mucuri. Diamantina, 2014.

26. ORTIZ, Fabiana. Mais de 400 projetos tramitam no Congresso para redefinir limites de UCs. Disponível em http://www.oeco.org.br/noticias/27875-mais-de-400-projetos-tramitam-nocongresso-para-redefinir-limites-de-ucs/ Acesso em: 22/11/2016.

27. REDE NACIONAL PRÓ-UNIDADES DE CONSERVAÇÃO. Agenda Mínima para as Unidades de Conservação 2015-2018. Curitiba, 2014. Disponível em: file://C:/Users/Usuario/Downloads/ agenda_uc_2015\%20(1).pdf Acesso em: 07/02/2017.

28. RIBAS, Rodrigo Pinheiro; GONTIJO, Bernardo Machado. Mapeamento dos Limites Oficiais do Mosaico de Áreas Protegidas do Espinhaço: interatividade entre o geoprocessamento e a gestão integrada do território. RBC. Revista Brasileira de Cartografia (Online), v. 67, p. 1641-1650, 2015.

29. RIBEIRO, Ana Pimenta. A caligrafia da sociedade na paisagem: transformações no entorno de unidades de conservação da Serra do Espinhaço - MG. Dissertação de Mestrado. Centro de Desenvolvimento Sustentável. Universidade de Brasília. Brasília, 2013. 
30. RIBEIRO, Eduardo Magalhães et. al. Gestão, uso e conservação de recursos naturais em comunidades rurais do Alto Jequitinhonha. Revista Brasileira de Estudos Urbanos e Regionais, 77-99. 2011.

31. SAADI, A. A Geomorfologia da Serra do Espinhaço em Minas Gerais e de suas Margens. Geonomos, Belo Horizonte,3(1): 41-63, 1995. (p.41-63)

32. SATHLER, Evandro Bastos. Os “Espaços de Incerteza”, a "Desterritorialização Subjetiva” e o "Pacto da Conservação": perspectivas de uma geografia socioambiental das áreas naturais protegidas. Tese. Doutorado em Geografia - Universidade Federal Fluminense. Niterói, 2010.

33. SCALCO, R. F. ; GONTIJO, B. M. . Aspectos Legais Relacionados à Criação de Unidades de Conservação de Proteção Integral e Territórios Quilombolas. In: V Congresso em Desenvolvimento Social, 2016, Montes Claros. Anais do V Congresso em Desenvolvimento Social. Monte Claros: Unimontes, 2016. v. 1. p. 1-14.

34. SCALCO, Raquel Faria; SOUZA, Daniella Eloi de. Área de Proteção Ambiental Estadual das Águas Vertentes: instrumentos de gestão e potencial turístico. Caderno Virtual de Turismo, 2016. (no prelo)

35. SOUZA, Daniella Eloi de. As Implicações da Criação do Parque Estadual do Biribiri para a Comunidade e para o Desenvolvimento do Turismo. Trabalho de Conclusão de Curso. Graduação em Turismo. Faculdade Interdisciplinar em Humanidades. Universidade Federal dos Vales do Jequitinhonha e Mucuri. Diamantina, 2011.

36. SOUZA, Daniella Eloi de; SCALCO, Raquel Faria; XAVIER, Kelsilene Fernanda. As Implicações da Criação do Parque Estadual do Biribiri para a comunidade e para o Desenvolvimento do Turismo. In. Caderno de Geografia, v.22, n.38. Belo Horizonte, 2012.

37. SOUZA, Daniella Eloi de. Aspectos Socioambientais e a Gestão da APA Estadual das Águas Vertentes. Dissertação de mestrado. Programa de Pós-graduação em Geografia. Instituto de Geociências. Universidade Federal de Minas Gerais. Belo Horizonte, 2014.

38. SOUZA, Herbert Amaro Aurélio. Oficinas de Legislação Ambiental e Turismo para Comunidades do Entorno do Parque Estadual do Biribiri. Trabalho de Conclusão de Curso. Graduação em Turismo. Faculdade Interdisciplinar em Humanidades. Universidade Federal dos Vales do Jequitinhonha e Mucuri. Diamantina, 2011.

39. SOUZA, Luiz Fernando de; STUMPF, Paola Prates; ZANCHET, Rovena. Manual de Apoio à Atuação do Ministério Público: unidades de conservação, criação, implantação e gestão. - 1 . ed. - Porto Alegre : Andrefc.com Assessoria e Consultoria em Projetos, 2015.

40. SOUZA, Carlos Henrique Silva; SANTIAGO, Maíra Pereira; FÁVERO, Claudenir; LOURES, Rosamaria Santana Paes; MENDONÇA, Vinícius Souza; BARROS, Bruna Lara Alvarenga. Cartografia Social como Instrumento de Análise Territorial e Luta por Direitos pelas Comunidades Quilombolas do Município de Diamantina-MG. In. Cadernos de Agroecologia. Vol. 8, No. 2, Nov 2013.

41. STCP ENGENHARIA DE PROJETOS LTDA. Plano de Manejo do Parque Estadual do Pico do Itambé. Curitiba, 2004a. 
42. STCP ENGENHARIA DE PROJETOS LTDA. Plano de Manejo do Parque Estadual do Rio Preto. Curitiba, 2004b

43. STCP ENGENHARIA DE PROJETOS LTDA. Plano de Manejo do Parque Estadual do Biribiri. Curitiba, 2004c.

44. UNITED NATIONS ENVIRONMENT PROGRAMME. Protected Planet Report 2016: how protected areas contribute to achieving global targets for biodiversity. Cambridge UK and Gland, Switzerland. 2016.

ARTIGO RECEBIDO EM ABRIL DE 2017

ARTIGO APROVADO EM AGOSTO DE 2017 